\title{
Paradigm Shift In Assessment Methodology For Law Students In South Africa
}

Deidre Joubert, BProc, LLM, LLD, ADHE (Cum Laude) Vaal University of Technology, South Africa

\begin{abstract}
This paper addresses the insufficient traditional method of assessment of tests and examination, which is purely the regurgitation of information. Unfortunately some lecturers tend to cling to the traditional method of assessment as it is an easy route for them to follow. The said method does not encourage the students to become critical thinkers and problem solvers, which is of the utmost importance to any student studying law-or law related qualifications. Deep learning is therefore not stimulated, because the students only study what they think is necessary to pass a test or examination paper. All that the traditional method of assessment results in is that a student, after completion of his/her studies, is not able to apply the knowledge which he/she so freely regurgitated. There is therefore no practice based learning taking place and assessment is not learner centred. A definite paradigm shift is necessary in order to ensure that deep learning is achieved by all students and that the students will be fully productive in legal practice when they complete their qualifications (graduateness). In order to implement and facilitate this said paradigm shift, the author addresses the definition of assessment, the purpose of assessment and the difference between deep- and surface learning. The different possible forms, instruments, methods and tools of assessment which the Legal Sciences Department at the Vaal University of Technology could use are addressed. Types of evidence of learning are considered and suggestions are made on best practice in respect of assessment methodology for students in the said department. The motivation and training of the lecturers are also of paramount importance and therefore the author also pays attention to these aspects in this paper. Once lecturers and students realise that it is to the benefit of the students to make assessment learner centred and the importance of constructive alignment, the shift to innovative assessment methods is easy. Students are then assured of holistic development and confident that they will be immediate assets to practice once they complete their qualifications and not burdens to their new employers that requires further training.
\end{abstract}

Keywords: Assessment; Legal Sciences; Best Assessment Practice; Motivation; Training; Lecturers; Constructive Alignment; Holistic Development; Graduateness; Practice Based Assessment

\section{INTRODUCTION}

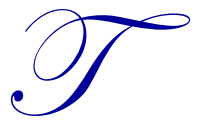

his paper addresses the author's view on ideal assessment strategies in the Department of Legal Sciences at the Vaal University of Technology in South Africa. The department presents a variety of qualifications ranging from legal qualifications, to policing- and forensic investigation qualifications, to occupational health and safety qualifications. In addition approximately thirty legal subjects are presented by the department to students studying other qualifications at the university. In light of the types of qualifications and subjects presented, it is important to create critical thinkers and successful problem solvers who will most probably also be knowledge creators in future and therefore there must be a paradigm shift toward the assessment philosophy set out in this document. There was a reliance on tests, assignments and exams to assess students and this lead to simple regurgitation of information by the students. A paradigm shift had to be motivated and implemented in respect of assessment in the department. 


\section{ASSESSMENT - ASPECTS CONSIDERED AND IMPLEMENTED IN THE DEPARTMENT OF LEGAL SCIENCES}

\subsection{What is assessment?}

Assessment can be defined as the way or process in which lecturers endeavour to ensure that students have acquired sufficient knowledge and skills in order to become productive and competent people in the workplace. The South African Qualifications Authority (SAQA) (2001:16) defines assessment as: “...a structured process of gathering evidence and making judgements about an individual's performance in relation to registered national standards and qualifications." Assessment is an integral part of learning, but what must not be forgotten is that assessment methods affect student learning. Principles of good practice (assessment) as stipulated in the SAQA document (2001:16-19) must be adhered to. In order to ensure that assessment is reliable, it must be consistent. For it to be valid, it must assess what they set out to assess and not what is easy to assess. Assessment is transparent if all stakeholders understand the system and it is well planned, practicably executable and properly regulated. Ethics is at the root of this system.

\subsection{The purpose of assessment}

Assessment purpose or learning outcomes determines when and how the student will be assessed and which assessment methods and techniques will be used in order to reach the specific outcome. An educator should define the outcomes and construct the assessments in such a way that the student achieves all said outcomes in line with the Intended Learning Outcomes for the different National Qualifications Framework (NQF) levels, in order to ensure that the student will be able to apply the knowledge gathered and be able to think critically and solve problems.

\subsection{Deep- versus surface learning}

\subsubsection{Surface learning}

With surface learning the foci are on unrelated sections or parts of the task and information is simply memorised and reproduced by the student. The students accumulate facts and concepts and are not able to differentiate principles from examples. The emphasis is external, in other words, from what is expected in the assessment, which is usually the reproduction of information learned. Conventional or traditional assessment, such as tests, assignments and written examinations, therefore fuel surface learning.

\subsubsection{Deep learning}

Deep learning relates to previous knowledge and new knowledge. Knowledge and information from different courses or subjects are seen as related to each other and theory is related to everyday experiences. Distinction is made between evidence and argument, and information must be organised and content structured into a coherent whole. The emphasis is therefore internal, in other words from within the student him/herself. By ensuring the participation of the student by deep learning, it is experienced as exciting and a gratifying challenge. (Atherton 2010) Deep learning involves high order cognitive skills and therefore the students will be able to refer to all knowledge gathered, not only the new knowledge and be able to make connections and actively search for meaning and understanding. Geyser states that: "deep learning approach is a prerequisite for the realisation of significant learning and the development of critical thinking." (Gravet and Geyser 2004:92) The author of this paper wholeheartedly agrees with this statement.

\subsection{Forms of assessment}

\subsubsection{Traditional assessment}

This is assessment by means of age old practice such as set exam papers, tests and assignments. This type of assessment promotes surface learning. This was the predominant assessment methodology used in the department. Unfortunately it was regarded as the easiest way to assess a student. Only the student's knowledge is 
assessed and not whether the student is able to apply this gained knowledge in industry or practice. There is a place for this form of assessment, but it should be used in conjunction with the alternative forms of assessments to ensure a student's achievement of the Intended Learning Outcomes required for the specific NQF level of the subject.

\subsubsection{Alternative assessment}

Different forms of assessment can be used to ensure deep learning and in turn it ensures that the students become critical thinkers and successful problem solvers. The use of these methods will ensure the shift to deep learning and move away from traditional assessment where students only regurgitate information. It is expected from the students to create a response to a question or a task. Students become active participants rather than expecting others to fill their heads with knowledge. The following forms of assessment are now used in the department, alone or in combination, depending on the outcomes required:

\subsubsection{Diagnostic assessment}

This is the first form of assessment used in higher education and serves to determine a student's strengths, weaknesses and prior knowledge of the subject. It also provides information on the potential of a student to complete a course and whether the student is in need of a bridging course before enrolling at a university. The results of this form of assessment can also assist in determining possible intervention or remedial actions to be taken in order to improve that student's learning ability and success. This assessment are also used if a student is identified as an "at risk student". An "at risk student" is a student that is found not competent and fails to satisfy the Intended Learning Outcomes for the specific subject's NQF-level.

\subsubsection{Formative assessment (learning from assessment)}

In order to establish the progress of learning, formative assessment is used. This is done during the process of learning and the purpose is to identify the strengths and weaknesses of each student, as well as in the lecturing style of the lecturer. The results are used for immediate feedback, either by the educator to the student or by the students or peers to the educator or fellow student. Learning may then be improved or even the lecturing methods will be adjusted by the educator in order to ensure an improvement in learning. Formative assessment motivates students to identify their own learning style or -preference, to identify each student's needs, promote deep learning and serves as a consolidation and profile of work completed to date. This type of assessment is also used to determine what the student knows about a certain topic before it is discussed in class. These periodic assessments provide information to the lecturer in order to adjust the teaching and learning methodology and information to be readdressed.

\subsubsection{Summative assessment (learning for assessment)}

A summative assessment is completed at the end of the learning experience or module. Through this assessment it is determined whether the student is competent. Final grading will then take place. The summative assessment should not consist of only an examination, as it will only assess a sample of learning. Different assessment methods should preferably be used for the summative assessment.

\subsubsection{Authentic assessment}

This type of assessment entails the posing of "real" tasks that requires the students to perform or produce knowledge instead of reproducing information learned. It is a multidimensional process of assessing students' acceptable performance in life-like role applications. Examples are for instance, to request the law students to conduct a moot-court, take down a witness statement, draw a legal opinion on a legal question, investigate a crime scene and gather evidence, inspect a construction site in order to assess safety measures adhered to by the contractor, etc. Students have to implement all the previous and new knowledge acquired into real life situations. Once again this stimulates critical thinking and problem solving and the assessments are practice based. 
This assessment methodology is now implemented in the department in the form of credit bearing Work Integrated Learning modules throughout the years of study of the qualifications presented in the department. Work and/or practice based activities are presented and assessed in order to ensure the graduateness of the students after completion of their studies. These activities are assessed by practitioners in industry and moderated internally. By using this type of assessment students realise how theory and practice form a whole and they are equipped to be fully functional practitioners directly after graduating. No further practical training by the employer will be necessary.

\subsubsection{Norm referenced (quantitative) assessment}

With this type of assessment comparisons are drawn between students, in other words judgments are made of the students themselves as persons. In this instance a percentage is given to a student and then compared to the percentages that other students achieved. In this instance students experience being compared to other better performing students and can easily see themselves as incompetent or not as able as other people. This is a situation that should be avoided if possible. This type of assessment is therefore not recommended and is currently not implemented in the department.

\subsubsection{Criterion referenced (qualitative) assessment}

Here the performance of a student is judged and it is possible to determine whether the student has achieved the competency and applicability criteria for the specific outcomes that had to be achieved. The student's skills, effort, learning and competence are assessed. This type of assessment is closely related the authentic assessment.

\subsection{Who should assess?}

Traditionally the lecturer is the agent that assesses the student in setting the criteria, selecting the evidence and making a judgment about whether the criteria has been met by the student. A lecturer could still assess students, but it is advisable that others also participate in assessments. Peer-assessment is when fellow students assess the participation and performance of a fellow student. This ensures participation in and transparency of assessment. Students become actively involved and not only rely on the sometimes subjective assessment by the lecturer. Peerassessment is done continuously during learning activities.

Self-assessment refers to the student assessing his/her own progress and performance in a reflective manner. The student is also given the opportunity to reflect emotionally on his/her performance and learning progress, which in turn will stimulate a will to achieve more.

Self-reflection can assist students in planning a task, monitor their own progress and evaluating and value their own accomplishments. This is a valuable tool in empowering learners to take control of their own learning experience, thinking and management of life in and out of university. (Gravet and Geyser 2004:105)

\subsection{Assessment instruments and methods}

The methods used by the assessor are usually observation and evaluation. As for the instruments, the author highlights but a few:

\subsubsection{Assessment under timed invigilation: Exam- or test conditions}

This is the easiest way for a lecturer to assess a student's recall of information. Unfortunately it stimulates surface learning as the students tend to memorise facts that they can reproduce in the exam in the timed context. This also creates a negative backwash. The "backwash" indicated here refers to the stimulation of a student's motivation to only study what they expect will be asked and/or to study the bare minimum which they are of the opinion is necessary to pass the subject. 


\subsubsection{Oral assessments}

This type of assessment is unreliable and creates the same negative backwash as stated above. Deep learning is not achieved.

\subsubsection{Multiple-choice questions}

Multiple-choice questions could test a student's knowledge and skills to a certain extent, depending on the manner in which such questions are drafted. It is recommended to use this instrument of assessment only to determine a basic knowledge of the material. It is useful to encourage class attendance, by having these assessments on a regular basis, but it encourages students to answer in a guessing manner and not really concentrate on providing the correct answer by analysing the question asked.

\subsubsection{Other examples}

Examples of alternative assessment instruments are presentations, case studies, reflective journals and portfolios of learning evidence, written legal opinions, moot courts, role plays, practical crime scene investigation and gathering of evidence, simulations, etc. These forms of assessment instruments are implemented in the department with positive results and -feedback from the students.

\subsection{Tools for assessment of instruments}

In order to assess the student's ability to satisfy the Intended Learning Outcomes, the tasks or assignments must be in line with the Intended Learning Outcomes for the different NQF-levels, which in turn must adhere to the SAQA level descriptors and coincide with the expectations of industry or practice (constructive alignment). Evidence of learning could be provided by the student (maybe as a summative assessment such as a reflective journal), which is then assessed by using an assessment rubric which addresses the ILO's in its entirety. Once again it is suggested that the assessment must be conducted in a holistic manner. A conceptual framework or rubric that enables the lecturer to see the relationship between the parts and the whole is drawn by the lecturer. Bloom's taxonomy and the SOLO taxonomy of: structure, observation, learning and outcomes, could be useful to ensure adherence to the outcomes. Other examples are memorandums or marking schemes.

It is in the best interest of the student to assess an essay in a holistic manner. The lecturer must remember that the point of an essay is to establish whether a student has the capability to respond to a question in a structured manner and whether he/she is able to make use of reflective writing.

\subsection{Types of evidence of learning}

The following evidence of learning are used and assessed in the department:

Direct evidence, such as assignments, tests, and written exams are not the only types of evidence of learning considered. Indirect evidence such as evidence which third-parties produce in respect of the student, such as awards, testimonials, external evaluations of Work Integrated Learning activities, etc. also plays a role. Historical evidence indicates to the assessor what the learner was capable of doing in the past, for instance portfolios and extended assessment. This last type of learning evidence is the most important and is currently being implemented in addition to direct evidence in the department, in the Work Integrated Learning modules. The student is mentored and assessed continuously and therefore is able to realise his/her own skills development and ability to apply theory to practice.

\subsection{Feedback}

In all the above, one of the most important aspects to remember is feedback, which must be given timeously and constructively. Without proper detailed and continuous feedback the purpose of assessment is in vain. Students must realise where they could improve and be given the opportunity to do so in order to ensure the achievement of the expected outcomes. 


\section{CONCLUSION}

The lecturers in the Department of Legal Sciences mainly made use of the traditional assessment method which consisted of set tests, exam papers and assignments, because it was the easiest route to follow. This was due to the large classes that are taught by the lecturers, heavy workloads and a lack of training in assessment methods. Unfortunately deep learning was not promoted and there was definitely room for improvement in respect of assessment in the department. All the aspects addressed above are now taken into consideration and implemented where practicable.

In order to implement this paradigm shift in assessment, the lecturers are trained and most of them are studying or have attained an Advanced Diploma in Higher Education, in order to be fully equipped to realise this paradigm shift. This is of importance because all the lecturers in the department come from legal practice or industry and have no previous training in teaching and learning. It is crucial for the lecturers to appreciate the benefits of changing assessment practices in the department, before the students will realise the benefit of experiencing new and innovative assessment methods. By equipping the lecturers with the requisite knowledge in respect of alternative assessment, they are geared to motivate the students to accept these new assessment activities and participate enthusiastically. Learner centred assessment is then achieved.

It is also of paramount importance that the Head of Department realises and appreciates the need for this paradigm shift in order to motivate and lead the lecturers in the department to implement the changes effectively. Without a transformational leader it will be impossible to implement these changes effectively. Granted, these alternative forms of assessment impacts on the workloads of the lecturers and therefore the Head of Department must ensure a reduction in student numbers per lecturer, by for instance employing additional lecturers.

Assessment in the department is now therefore predominantly learner centred and prepares the students to become knowledgeable, competent and skilled employees immediately after graduation (graduateness), who do not need any further training by the employer.

\section{AUTHOR INFORMATION}

Dr. Deidre Joubert obtained a BProc-degree and practiced as an attorney for 20 years. After joining the Vaal University of Technology as a lecturer, she obtained a LLM-degree (Master of Laws), a LLD-degree (Doctor of Laws) and an Advanced Diploma in Higher Education (Cum Laude). She is currently Head of the Department of Legal Sciences at the Vaal University of Technology in South Africa. E-mail: deidre@vut.ac.za

\section{REFERENCES}

1. Adams, J. Assessment. Montana State University. http://www.montana.edu/teachlearn/Papers/assessment.htm Retrieved on 17 July 2010.

2. Anonymous. Position Paper on Assessment. Oxford Brookes University. http://brookes.ac.uk/aske/positionpaper.html Retrieved on 17 July 2010.

3. Anonymous. Assessment Strategies and Definitions. The Teacher's Internet Use Guide. http://www.rmcdenver.com/useguide/assessme/definiti.htm Retrieved 18 July 2010.

4. $\quad$ Atherton, J.S. 2010. Learning and Teaching: Deep and Surface learning. http://www.learningandteaching.info/learning.deepsurf.htm Retrieved on 17 July 2010.

5. $\quad$ Atherton, J.S. 2010. Learning and Teaching: SOLO Taxonomy. http://www.leaningandteaching.info/learning/solo.htm Retrieved on 17 July 2010.

6. Atlas, D. 2006. Alternative Assessment: Authentic Assessment: A Practical Application. http://www.montana.edu/teachlearn/Papers/altassess.htm Retrieved on 18 July 2010.

7. Biggs, J. and Tang, C. 2007. Teaching for Quality Learning at University. McGrawHill. London.

8. Gravet, S. and Geyser, H. 2004. Teaching and Learning in Higher Education. Van Schaik Publishers. Pretoria.

9. McDowell, L. 2007. Using assessment to drive the learning-but what about the learners? http://www.brookes.ac.uk/aske/perspectives.html Retrieved on 17 July 2010. 
10. Rust, C. 2002. The impact of assessment on student learning. Active learning in Higher Education. http://alh.sagepub.com/cgi/content/abstract/3/2/145 Retrieved on 16 July 2010.

11. South African Qualifications Authority. 2006. Refined Level Descriptors for a 10-Level NQF. http://www.saqa.org.za/docs/legislation/notices/2006/leveldescriptors2.html Retrieved on 3 August 2009.

12. South African Qualifications Authority. 2001. Criteria and Guidelines for Assessment of NQF Registered Unit standards and Qualifications. 
NOTES 